Geopolítica(s) Revista de estudios sobre espacio y poder ISSN: 2172-3958

https://dx.doi.org/10.5209/geop.69020

\title{
La Europa indolente. Una hipótesis sobre los efectos geopolíticos de la pandemia
}

Juan Romero ${ }^{1}$

Recibido: 24 de abril de 2020 / Aceptado: 10 de mayo de 2020

Resumen. La Unión Europea afronta lo que tal vez pudiera ser su última oportunidad para consolidar un proyecto político tan original como necesario. De los acuerdos políticos que se adopten para hacer frente a los efectos de la pandemia global dependerá que el proyecto salga reforzado o que se acentúe la crisis existencial y de legitimidad que hace tiempo se evidencia. Es el momento histórico para demostrar que desea ser algo muy distinto a una unión de mercado: una comunidad política. De otra parte, también puede ser una oportunidad para consolidarse como referente moral en defensa de una sociedad decente y como "tercer espacio" geopolítico en un mundo nuevo, sin centro, caracterizado durante las primeras décadas del siglo XXI por cierto (des)orden geopolítico, debido al declive relativo de EE UU y al ascenso relativo de China.

Palabras clave: pandemia de COVID-19; Unión Europea; (des)orden geopolítico; geografía moral; renta básica.

\section{[en] The Indolent Europe. A Hypothesis about the Geopolitical Effects of the Pandemic}

\begin{abstract}
The European Union is facing perhaps its last chance to consolidate a political project as original as it is necessary. The political agreements that are adopted to face the effects of the global pandemic will depend on whether the project is strengthened or that the existential and legitimacy crisis that has been evident for some time is accentuated. This is the historic moment to demonstrate that you want to be something very different from a market union: a political community. On the other hand, it can also be an opportunity to consolidate as a moral bench-mark in defense of a decent society and as a geopolitical "third space" in a new world, without a center, characterized during the first decades of the 21 st century by a certain geopolitical (dis)order, due to the relative decline of the US and the relative rise of China.
\end{abstract}

Keywords: COVID-19 pandemic; European Union; geopolitical (dis)order; moral geography; basic income.

1 Cátedra de Geografía Humana e Instituto Interuniversitario de Desarrollo Local, Universitat de València.

E-mail: Juan.Romero@uv.es 
[pt] A Europa indolente. Uma hipótese sobre os efeitos geopolíticos da pandemia

Resumo. A União Europeia está enfrentando talvez sua última chance de consolidar um projeto polí-
tico tão original quanto necessário. Os acordos políticos adotados para enfrentar os efeitos da pande-
mia global dependerão do fortalecimento do projeto ou da acentuação de sua crise existencial e de
legitimidade que é evidente há algum tempo. Este é o momento histórico para demonstrar que você
quer ser algo muito diferente de uma união de mercado: uma comunidade política. Por outro lado,
também pode ser uma oportunidade de se consolidar como referência moral em defesa de uma socie-
dade decente e como "terceiro espaço" geopolítico em um novo mundo, sem centro, caracterizado nas
primeiras décadas do século XXI por uma certa (des)ordem geopolítica, devido ao declínio relativo
dos EUA e à ascensão relativa da China. Palavras-chave: pandemia da COVID-19; União Europeia; (des)ordem geopolítico; geografia moral; renda básica.

Sumario. 1. Crisis existencial. 2. ¿Una comunidad política? Coda. Referencias.

Cómo citar: Romero, J. (2020). La Europa indolente. Una hipótesis sobre los efectos geopolíticos de la pandemia. Geopolítica(s). Revista de estudios sobre espacio y poder, 11(Especial), 25-37.

\section{Crisis existencial}

Hace demasiado tiempo que la Unión Europea navega a la deriva. Sin rumbo y sin alma (Ortega, 2017b). Incapaz de dar respuesta a las distintas crisis que afronta (Castells, 2018), empezando por la crisis existencial y de legitimidad. Las evidencias de una creciente desafección y el aumento del euroescepticismo son incontestables a la vista de las numerosas series publicadas (Aixalà, 2014; Pew Research Center, 2016; Eurobarómetros, varios años). En uno de los momentos históricos más inciertos, cuando asistimos al desguace del orden mundial nacido en la postguerra, vamos en la dirección equivocada. Europa es ahora el problema para millones de europeos, el proyecto político se diluye gradualmente, las sociedades se fracturan y los pueblos se repliegan y se rodean de muros reales y metafóricos. Se han levantado nuevos telones morales (Rizzi, 2019). Y mientras esto ocurre las élites políticas y económicas no solo son incapaces de dar una respuesta europea coordinada y solidaria, aportando soluciones globales a desafíos globales y soluciones comunes a problemas comunes, sino que sus decisiones son una clara muestra de involución tan insensata como lesiva. Hace una década no lo habría dicho, pero ahora no lo descarto: si no se cambia el rumbo creo que el proyecto político europeo puede naufragar.

De otra parte, la Unión Europea hace tiempo que renunció a ser un actor geopolítico global y tal vez un referente moral. Disponemos de unas capacidades extraordinarias, pero somos incapaces de aportar soluciones comunes a desafíos supraestatales. Hemos preferido anteponer egoísmos nacionales, protagonizando con nuestras contradicciones y actitudes insolidarias nuestro propio naufragio moral y político (De Lucas, 2015) mientras EE UU y China se convertían en los árbitros del siglo XXI. Asistimos en directo al inicio de una nueva era y nos ha sorprendido desprovistos de voluntad política, instrumentos y estrategias compartidas. Si no 
somos capaces de entender el momento histórico actual estaremos condenados a ser actores políticos subalternos. En geopolítica, como alguien dijo alguna vez, si no estás sentado en la mesa es porque formas parte del menú.

Ya sabemos que nunca podremos ser los Estados Unidos de Europa, ni podremos disponer de un auténtico presupuesto federal, ni siquiera un Banco central con similares competencias a la Reserva federal norteamericana. Pero nuestro original proyecto, inacabado, ofrecía la posibilidad de seguir avanzando. En el mundo existen grandes Estados federales, muy poblados, multiculturales, que no obstante son una nación. Entre ellos, Estados Unidos, Méjico, Brasil, India, Nigeria... y otros muchos. El caso europeo es distinto. Nos encontramos ante un proyecto político ahora integrado por 27 Estados que no tienen, ni tendrán nunca, sentimiento alguno de pertenencia a una nación. Incluso es discutible que sus ciudadanos tengan de forma mayoritaria sentimiento de pertenencia a una misma cultura. El caso de la Unión Europea es todavía más complejo desde el momento en que no todos los ciudadanos en los 27 Estados miembro albergan el sentimiento de pertenencia a un Estado-nación, puesto que en algunos de ellos existen distintas naciones en su seno. La realidad muestra la existencia de decenas de naciones (más que Estados) que no tienen interés alguno en potenciar un proyecto político del tipo Estados Unidos de Europa o cualquiera de las versiones de Estados-nación grandes como los enunciados más arriba. Y sin embargo, se habría podido construir un proyecto político sólido sobre las bases plasmadas en nuestros Tratados.

La UE nació como respuesta a un momento histórico excepcional: la necesidad de evitar una nueva guerra entre europeos, la Guerra Fría, la urgencia de legitimación política y moral de Alemania e Italia y la aspiración de Francia de reforzar su papel como actor global, explican en gran medida su origen y el gran pacto político que lo hizo posible. Lo cierto es que hubo enemigos que se transformaron en vecinos y ello propició el mejor periodo histórico de los pueblos europeos. El contexto geopolítico y socioeconómico eran favorables y el momento histórico tan excepcional como irrepetible: el Atlántico como centro geopolítico del mundo, crecimiento demográfico sostenido, pleno empleo sin inflación y sistemas fiscales saneados con capacidad de impulsar políticas públicas que entonces no eran políticamente divisivas. En ese contexto se explica la construcción de Estados de Bienestar de inspiración keynesiana robustos y la reducción de niveles de desigualdad como nunca antes en la historia durante más de tres décadas. La resignación reformadora, como lo definió Rosanvallon (2012), se cimentó en ese momento histórico tan excepcional como irrepetible. Pero desde hace más de dos décadas el contexto es completamente distinto desde cualquier punto de vista que se mire: geopolítico (el centro de gravedad se ha desplazado hacia el Pacífico en un mundo crecientemente multiunipolar), demográfico (nuestro problema ahora es afrontar las consecuencias del envejecimiento), de creación de empleo suficiente y decente, hemos de gestionar los efectos de la profunda deslocalización de la actividad industrial y de gestión de la deuda pública.

Nuestras sociedades se han fracturado y precarizado de la mano de los grandes desacoplamientos del siglo XXI. Son los efectos de la política económica de la inseguridad, como explicaron Beck (2012) y Sennett (2006) y que han desembocado en las nuevas sociedades precarias (Standing, 2011, 2017). Del horizonte ascendente de la segunda mitad del siglo XX hemos pasado a poner en marcha el descensor social (Nachtwey, 2017). Aumentan los niveles de desigualdad, adelgazan 
las clases medias tradicionales (Guilluy, 2019; Vacas, 2019). Se ensancha la fractura entre el Norte y el Sur de Europa, se ensancha la brecha entre el $10 \%$ de arriba y el $10 \%$ de abajo, una cuarta parte de europeos está en serio riesgo de exclusión, millones de jóvenes europeos no ven con confianza su futuro y no se aprecian progresos (Ariño y Romero, 2016).

La forma de conducir la globalización económica ha dado lugar a nuevas geografías del malestar, una nueva geografía de territorios y personas que no importan en todas las democracias liberales (Guilluy, 2014; Dijkstra, Poelman y RodríguezPose, 2019; Romero, 2019). Las fracturas sociales han agudizado las fracturas políticas entre los Estados miembro y en el seno de cada uno de ellos y acentuado el vaciamiento del centro político. La Cuestión Social hace tiempo que ha regresado a nuestras sociedades occidentales (Romero, 2013). Se agudizan los conflictos sociales y culturales interclasistas e intraclasistas. Emergen nuevas geografías del odio y el resentimiento. Haríamos bien en no olvidar la afirmación lapidaria de Tony Judt al respecto: "como sabían muy bien los grandes reformadores del siglo XIX, la Cuestión Social, si no se aborda, no desaparece. Por el contrario, va en busca de respuestas más radicales" (Judt, 2008, p.416).

Vivimos un momento histórico en el que ya no existen grandes relatos. A las puertas del fracaso de la utopía globalista neoliberal, el mundo de las izquierdas, también fracasadas, instalada en su melancolía, se siente incapaz de construir un relato consistente y coherente para esta nueva era. Lo ha explicado de forma magistral Enzo Traverso: la "cesura histórica" de finales de los ochenta significó el final de las utopías del siglo XX. Los nuevos movimientos que se inician a partir de ese final anticipado del siglo XX ya no son una continuidad de los movimientos anteriores. El siglo XXI ha surgido sin utopías, sin "horizonte de espera". Los marcos de transición de la memoria, los vínculos con el pasado, se rompieron y la política del siglo XX, con sus partidos y sindicatos de masas, ya son historia. En ese tiempo, los movimientos sociales otorgaban a cada uno un sentido de pertenencia que trascendía a su propia situación individual. Esta cesura histórica explica por qué las nuevas revueltas sociales no se remiten a antiguos relatos ni utopías. Carecen de árbol genealógico, y esa puede ser su fuerza, pero en el momento presente es su debilidad. Tienen una gran fuerza creadora, pero al no inscribirse en una tradición histórica tienen un carácter efímero. Estaríamos así ante un "mundo comprimido en el presente" marcado por una aceleración permanente del tiempo sin relato proyectado hacia el futuro (Traverso, 2019).

Las sociedades también se repliegan, refuerzan o reconstruyen sus identidades y emergen nuevas opciones nacional-populistas que hoy gozan de amplio apoyo electoral en todos los países de la Unión. En esa temporalidad el futuro genera miedos que no solo se explican por la economía. La inmigración percibida como problema, la brecha cultural entre comunidades, el temor a la destrucción de la comunidad y la identidad nacional, la sensación de ser mayorías amenazadas en su propio país, el choque de solidaridades y el temor a la privación relativa, la percepción de riesgo de desintegración del nosotros, el fracaso de los modelos de gestión de la multiculturalidad... y tantas otras cuestiones que no solo explican el malestar sino que erosionan como nunca antes el propio proyecto político europeo (Eatwell y Goodwin, 2019; Fukuyama, 2019; Krastev, 2019). 


\section{2. ¿Una comunidad política?}

La UE podría haberse legitimado como proyecto político original demostrando que quería ser mucho más que un proyecto de mercado común: una comunidad política. Conscientes de que nunca podríamos construir una identidad europea. Una Europa capaz de encarnar un nuevo propósito colectivo, un ideal político y un nuevo relato para una nueva Era. Una Europa inclusiva, no intrusiva. Una Europa política, no burocrática. Una Europa social, no una Europa asocial (Moreno, 2013). Dando sentido y contenido concreto a nuestros acuerdos, apelando a sus grandes principios de solidaridad entre los Estados, bienestar de los pueblos y defensa de la cohesión económica, social y territorial, empezando por fortalecer su pilar social. Haciendo realidad, con hechos, que existía voluntad política de culminar la hoja de ruta inicialmente trazada por los padres fundadores y los líderes de la primera etapa: unión monetaria, económica, fiscal y política. Desde los retos derivados de la pandemia y sus imprevisibles efectos, la crisis climática, la transición hacia nuevos modelos energéticos, la política migratoria común o la nueva revolución industrial, hasta el diseño de nuevas formas de gobernanza global, el establecimiento de nuevos instrumentos de regulación y control del sistema financiero o de nuevas reglas globales comerciales, fiscales (para implantar algún tipo de fiscalidad a transacciones y a la riqueza) o laborales a favor del trabajo decente y que limiten el riesgo de dumping social y ecológico, pasando por la obligación de reforzar la cooperación con los países en desarrollo donde las consecuencias económicas y sociales de la pandemia global pueden ser dramáticas. En especial con nuestra Frontera Sur así como Latinoamérica.

El marco europeo sigue siendo la solución pese a que ahora muchos lo perciben como problema. Estos procesos solo son gobernables desde la política europea, pero la respuesta a estas preguntas no puede ser más decepcionante: las elites que hoy gobiernan la Unión Europea no quieren ocuparse del futuro y los Estados de forma individual y separada no tienen capacidad para hacerlo. Esta es hoy la cruda realidad. Hemos tenido tres grandes oportunidades recientes. La Gran Recesión de 2008, la crisis de los refugiados, nuestro particular 11-S en palabras de Krastev (2019) y ahora la Gran Depresión de 2020. Y todas las ha desaprovechado. De modo que lo más probable es que de esta Gran Depresión salgan reforzadas las posiciones de repliegue constatadas desde hace tiempo, ahora agudizadas, favorecidas por la incomparecencia política de la socialdemocracia europea.

Si quisiéramos podríamos. Pero no queremos. No tenemos solo un problema de diseño sino de motor. No hemos entendido las crisis como oportunidad. Por esa razón es poco probable que prospere la idea de más Unión Europea tal y como muchos intelectuales europeístas defienden (Habermas et al. 2020) y algunos responsables políticos del Sur de Europa reclaman. Y lo sabemos desde hace mucho tiempo (Torreblanca, 2011; Pinyol, 2016). Gradualmente, también en Europa, se ha ido consolidando el momento vertical frente a otros momentos horizontales en nuestra historia reciente (Ortega, 2017a). Por eso es muy poco probable que prosperen iniciativas surgidas desde el Sur del tipo mutualización de la deuda (una de las líneas rojas históricas que será difícil que Alemania traspase) o Eurobonos.

Ha quedado claro que el problema no era Grecia, ni Portugal, ni España, ni Italia. El problema es esta forma de entender Europa. Cada vez va quedando más claro que en un futuro inmediato existen más riesgos que oportunidades. Que las 
elites europeas no quieren realmente ocuparse del futuro en clave inclusiva. Que no existen liderazgos morales claros para afrontar y gestionar esta situación. Que de seguir así, las cosas no mejorarán. Que además de las fracturas sociales que se amplían dentro de cada país, hay riesgos de fractura política. Que hay demasiadas señales de bloqueo o de posibilidad de desandar parte del camino. Que el proyecto político todavía puede naufragar.

También tenemos una realidad condicionada por la voluntad profunda de los diferentes pueblos. El problema no es Orbán, Salvini, Le Pen, Rutte, Kurz o tantos otros, sino que radica en la mentalidad y actitudes que anidan en el interior de millones de europeos inseguros y reclaman a sus gobiernos fronteras y muros en la equivocada creencia de que así mejorarán sus vidas. Regresan nuestros conocidos fantasmas. A medida que las generaciones de europeos ya no tienen el recuerdo de viejos enfrentamientos, a medida que se apagan las brasas de la guerra, esos fantasmas se hacen más presentes y ha regresado el irredentismo y el nacional populismo.

Cuando superemos esta guerra nueva (Castells, 2020), las cuatro Europas, la mediterránea, la nórdica, la central y la del Este, tendrán que explorar otras formas de cooperación reforzada. Lo que queda de Europa, habrá que afrontar, lo más unidos posible, la crisis financiera, el equilibrio de las cuentas públicas, la reconstrucción económica y la grave emergencia social, tan profundas como desconocidas, que vendrán después (OIT, 2020; FMI, 2020). Pero hasta ahora no hemos sido capaces de superar el atasco político en el que hace tiempo nos encontramos.

No obstante, y a diferencia de las posiciones mayoritarias impuestas en la Gran Recesión de 2008, la actitud de la mayoría de socios europeos ha cambiado ante el reto de hacer frente a los efectos de la Gran Depresión de 2020. Existe un cierto consenso en torno a la idea de que necesitamos acordar objetivos comunes nuevos y ambiciosos instrumentos de financiación para hacer frente a las tensiones futuras, pero todavía existen demasiadas resistencias. A lo máximo a lo que se puede aspirar en el momento de escribir estas páginas (inmediatamente después del Consejo Europeo de 23 de abril de 2020), y ha sido un acuerdo político muy difícil de alcanzar, es a la (ambigua) movilización de los recursos - muy probablemente será la combinación de créditos, avales y transferencias - puestos a disposición de las economías más vulnerables fruto del consenso alcanzado en el seno del Eurogrupo y el Consejo Europeo. Son decisiones acertadas, porque revelan que la voluntad de acuerdo se ha impuesto a la desconfianza, pero están muy lejos de la idea de Europa que nos haría más fuertes. Pese a todo, la propia existencia de la Unión Europea y formar parte de ella como Estado miembro es fundamental. Téngase en cuenta que sin la decisiva intervención del BCE en clave de Unión Europea - aun con sus limitaciones estatutarias-, la posibilidad del recurso al Mecanismo Europeo de Estabilidad, al BEI o la posibilidad, en su caso, de dar contenido a lo que el Eurogrupo ha definido como nuevos "instrumentos financieros innovadores", las situación de algunos países para afrontar las repercusiones económicas y sociales de la pandemia, España entre ellos, sería dramática. En consecuencia, las decisiones tomadas hasta ahora por bancos centrales, gobiernos y parlamentos y autoridades financieras son imprescindibles, pero podría no ser suficiente si no se da un paso más en la dirección de disponer de nuevos instrumentos fiscales.

La UE necesitará de una nueva agenda con nuevas reglas que permita mantener el euro y que mitigue los efectos del dumping social, fiscal y ambiental (también 
entre los propios Estados miembros); preservando lo esencial de pertenecer a un área de libre comercio con capacidad de interlocución con otros actores globales, a unas reglas monetarias, a una gradual armonización fiscal y tal vez a un espacio de defensa común. Y no es poco. Pero no es probable que se pueda aspirar a mucho más a la vista de la desconfianza existente y de las fracturas políticas Norte/Sur y de la distancia existente entre el Este y el Oeste. La mejor señal de que los Estados miembro estiman que una Europa unida es lo mejor para todos y cada uno, sería apostar por la creación de un fondo común para la recuperación social y económica. Y más allá de anuncios billonarios lo importante —que siempre está en los detalles y no en los anuncios- será constatar finalmente cuáles serán los contenidos de esos acuerdos en un futuro inmediato. Porque con los indicadores económicos y sociales que ya conocemos (OCDE, 2020; Banco de España, 2020) es urgente e insoslayable que el Consejo Europeo finalmente alcance algún tipo de acuerdo. No hacerlo en estas circunstancias históricas tan excepcionales significaría renunciar a la pervivencia del proyecto político y quién sabe si de la zona euro.

Habrá que dedicar esfuerzos a invertir la prolongada y creciente tendencia hacia el euroescepticismo. El reto será encontrar un equilibrio aceptable y una aplicación suficiente del principio de solidaridad. Y tampoco será sencillo, puesto que si las opiniones públicas del Norte perciben que se ha ido demasiado lejos en favor de los países del Sur, allí avanzarán expresiones euroescépticas; y a la inversa, si los ciudadanos del Sur entienden que la UE no ha sido solidaria con su situación, entonces el euroescepticismo avanzará en la Europa mediterránea. Es mejor que nos hagamos a la idea y trabajemos por consolidar aquello que sea posible, alcanzando acuerdos en el punto intermedio, pero sin grandes esperanzas ni apelaciones a los ideales de los padres fundadores. Aquella idea de Europa forma parte de aquel contexto y nada tiene que ver con el actual.

Hemos llegado hasta aquí por deméritos propios. Es mejor no afanarse en buscar fuera de nuestras fronteras los culpables de nuestro dulce declive. Una mezcla de falta de liderazgo, incapacidad para entender el actual momento histórico, indolencia, insolidaridad, arrogancia, falsa superioridad moral y ausencia de visión estratégica. No hemos sido capaces de impulsar políticas comunes (la únicas que merecen tal nombre son la PAC - aunque reducida en su presupuesto- y el programa Erasmus). Ni siquiera hemos sido capaces de atenuar los evidentes perjuicios derivados del dumping fiscal entre Estados miembro, No hemos querido entender que el mejor aliado de los nacional populismos es no hacer nada para impedir nuestro desvanecimiento político y la ausencia de una agenda social consistente, justa y solidaria. Pronto hemos olvidado nuestros anuncios de impulsar el Pilar Social. No hemos hecho lo suficiente en materia de investigación, educación y formación permanente. Tampoco para superar nuestra dependencia energética y tecnológica. Mucho menos para garantizar nuestro modelo industrial, casi desmantelado a causa de la deslocalización y cuyas consecuencias hemos comprobado ahora. Hemos estado a punto de hacer desaparecer nuestras agriculturas que hoy reconocemos como esenciales para garantizar nuestra soberanía alimentaria ¿Qué se ha hecho para impedir que los agricultores europeos (al igual que los del resto del mundo) sean meros asalariados precarios en sus propias explotaciones en beneficio de unos pocos monopolios agroindustriales globales? Carecemos de una política migratoria común. Hemos tocado fondo con la crisis de los refugiados... En 
definitiva, aquella vieja aspiración de unión monetaria, económica, fiscal y política quedó detenida e inacabada en su mismo inicio.

No será fácil avanzar en la puesta en marcha de políticas comunes en campos hoy fundamentales, y ese puede ser el origen de nuestro declive definitivo. A lo más que algunos parecen aspirar es a no regresar al punto de partida de la mano de los nuevos partidos europeos que reclaman el desguace de la UE y otros actores geopolíticos que anhelan nuestro debilitamiento. Sin embargo, existe un amplio margen de maniobra si se quiere reforzar la Unión Europea como actor global y como "tercer espacio geopolítico" entre EE UU y China. También si se asume que las fracturas económicas y sociales serán demasiado profundas como para no apostar por la reconstrucción a partir de grandes acuerdos en las distintas escalas (europea, estatal y regional-local). Por último, si se apuesta por la innovación, la sociedad digital, la creación de nuestras propias plataformas tecnológicas, la reindustralización, la transición energética o la defensa común, sin duda contribuiría a reforzar nuestra autonomía estratégica y ofrecer mayores seguridades.

Tampoco podemos atribuir a otros países de la UE todos nuestros problemas y déficit domésticos. Es cierto que las políticas austeritarias impuestas a la vieja periferia tras la Recesión de 2008 nos perjudicaron, pero también hemos de asumir nuestra responsabilidad como Estado miembro. No son responsables de nuestra baja productividad, de nuestro modelo de crecimiento, de nuestro sistema educativo, de nuestra baja calidad institucional, de la situación financiera de nuestras administraciones, de nuestra elevada deuda o de nuestro despilfarro de recursos públicos (Alcalá y Jiménez, 2018; Sebastián, 2019; Romero et al., 2019).

Tendremos que equiparnos mejor, explorando distintas soluciones adecuadas para cada contexto específico e impulsando estrategias de recuperación con fondos propios además de los comunitarios (Les Gracques, 2020). Por ejemplo, organización territorial del Estado y gobernanza territorial, calidad institucional y buen gobierno, estrategias de adaptación a la crisis climática, apoyo decidido a la sociedad digital, modelo formativo, reducción de las desigualdades, reto demográfico, innovación, transición energética, reindustrialización, soberanía alimentaria, nuevo modelo productivo y nuevo modelo de crecimiento, cohesión social y territorial, gobernanza metropolitana... Una agenda tan urgente como ambiciosa, que no admite más demoras, con la vista puesta en 2030-2050.

Nadie sabe qué nos depara el futuro. Ya hemos visto que cualquier cisne negro lo puede cambiar todo en quince días. Personalmente quisiera estar completamente equivocado en este análisis. Como viejo europeísta nada me haría más feliz. Pero, por si acaso, yo sugiero a nuestros responsables políticos, de gobierno y de oposición, que vayan pensando en un plan B distinto al propuesto por los nacional populismos para navegar en un contexto más desglobalizado, con formas de gobernanza europea más flexibles, con mayor margen de maniobra a escala estatal, con agendas regionales y locales reforzadas y con la vista puesta en otro modelo productivo y de crecimiento y otra forma de consumo. Algunos países europeos ya avanzan reflexiones al respecto, por ejemplo en sectores fundamentales como la industria (VV AA, 2020). Por eso yo también defiendo unos nuevos Acuerdos de Estado para el caso de España. Y casi tan importante (confío en que más probables), el impulso de pactos regionales y locales con programas de ayudas directas a familias para abordar la situación inédita de emergencia social, al tejido productivo y a las pequeñas empresas, acordes con el contexto específico e institucional y socioeco- 
nómico en cada caso y hasta donde la capacidad presupuestaria lo permita. Los tiempos excepcionales que vivimos y los desconocidos desafíos que se avecinan así lo exigen.

\section{Coda}

Como consecuencia de esta pandemia global en Europa también habrá ganadores y perdedores entre sus ciudadanos. No todos sufriremos por igual sus dramáticas consecuencias. Porque en cualquier guerra o crisis social profunda siempre han sufrido y sufren más los mismos. Con diferencias, según la parte del mundo y la familia en que hayamos nacido, pero los mismos. Los datos al respecto son concluyentes: la pandemia global afecta mucho más a los grupos de población con las rentas más bajas y a los países más pobres. Lo ha resumido de forma muy gráfica Flores D'Arcais: “(...) No hay nada peor que decir: estamos todos en el mismo barco. No, no es así. Estamos todos en el Titanic, pero los de tercera clase murieron más, porque los botes se los cogieron los de primera clase" (Domínguez, 2020).

La gran paradoja y a su vez gran enseñanza de esta pandemia global es que muchos de aquellos a los que nuestras democracias opulentas consideraban invisibles han resultado ser los realmente esenciales para garantizar el funcionamiento de nuestros servicios básicos. De ahí la urgente necesidad de impulsar sólidas políticas inspiradas en un keynesianismo inteligente en nuestras democracias. Con un gran objetivo prioritario durante la segunda mitad de 2020 y probablemente 2021: impulsar iniciativas que garanticen ingresos mínimos a las familias con menor renta y favorecer desde los poderes públicos que los bancos faciliten el pago diferido o fraccionado de los créditos a familias con menos ingresos. Si este no es el momento histórico propicio para hacer realidad un ingreso mínimo y ciudadano en nuestras sociedades ¿cuándo lo será? (Moreno, 2020). Del mismo modo, apostar por políticas en favor de mayor igualdad y por el control democrático de los monopolios y oligopolios globales debería ser una prioridad en los próximos años. También deberá ser un imperativo favorecer nuevas iniciativas de cooperación al desarrollo, en especial en nuestra Ribera Sur y el Sahel, uno de nuestros mayores desafíos geopolíticos, apostando por la importancia de la calidad institucional y abandonando viejas y fracasadas concepciones de cooperación al desarrollo y de intereses estratégicos disfrazados de ayuda.

Pero si se quiere mantener, o mejor, reforzar el proyecto político común no puede afianzarse la percepción de que existen Estados ganadores y otros perdedores, porque de esa forma el proyecto naufragará. De ese modo, puesto que no hay dulces declive, todos perderemos y saldremos más debilitados si no caminamos unidos. La "virtuosa" Europa calvinista y la "pecadora" Europa del Sur han de ser capaces de encontrar espacios de encuentro. Unos abandonando la desmemoria histórica, el cinismo político y el egoísmo nacional. Otros, demostrando con hechos (y contrapartidas) que son capaces de mejorar su calidad institucional y la eficiencia y eficacia de sus políticas. La Unión Europea necesita una legitimación de urgencia para afrontar, unidos hasta donde sea posible, los grandes desafíos que nos aguardan. Ensanchando el espacio público y acordando unidos una salida democrática a la Gran Depresión de 2020. Porque la unión y la solidaridad nos permitirán 
detener la sangría del euroescepticismo y tener mayor protagonismo en lo que podría ser el inicio de un nuevo (des)orden geopolítico mundial.

Es necesario elaborar un nuevo relato europeo para este nuevo tiempo impulsado desde el mundo de las izquierdas. Una hoja de ruta alternativa a la fracasada utopía globalista neoliberal, hegemónica en el terreno político y académico durante más tres décadas, que ahora muestras sus carencias con toda crudeza. Empezando por reconocer errores e interrogarse por las razones que nos han traído hasta aquí para no volver a incurrir en ellos ¿Por qué ha callado la socialdemocracia durante este tiempo de globalización acelerada impregnada de darwinismo neoliberal? ¿Por qué se apresuró a facilitar con su silencio la agenda neoliberal desbrozando el camino en los parlamentos apoyando tratados de libre comercio que básicamente favorecía a las grandes corporaciones? ¿Por qué no defendió un modelo propio, una alternativa consistente y coherente para este nuevo tiempo? ¿Por qué se extrañan ahora de su creciente irrelevancia política por la pérdida de apoyo entre amplias clases populares y clases medias en favor de nuevas formaciones nacional populistas? ¿Por qué más allá de la socialdemocracia tradicional, no se vislumbra ninguna opción con capacidad de convertirse en alternativa de gobierno? Hace mucho tiempo que sabíamos que no había "bases naturales" y una nueva coalición electoral del mundo de las izquierdas nada tiene nada que ver con la coalición histórica sino que ha de partir de la gran recomposición social ocurrida.

La batalla de las ideas será fundamental en el futuro inmediato y existe un amplio campo sobre el que vale la pena pensar. Desde hace años algunos defendemos que el mundo de las izquierdas puede proponer un programa de reformas para garantizar el futuro del modelo socioeconómico europeo. Cuando menos, una agenda política con propuestas creíbles y con mecanismos eficaces de gobernanza económica, capaces de proporcionar mayor confianza a los ciudadanos. Creemos que hay espacio para una agenda posible y distinta porque este nuevo tiempo permitirá contraponer, si hay voluntad, otros enfoques diferentes a los argumentos del pensamiento neoliberal. Porque las condiciones han cambiado, también en Europa, y los pilares sobre los que cimentar esa nueva agenda ahora cuentan con suficiente consenso: unión, gobernanza democrática, decencia, realismo, igualdad, equidad, austeridad en las formas de vida y consumo, sostenibilidad y solidaridad.

Algunos de los puntos de discusión más relevantes ya fueron parcialmente desarrollados en otro sitio (Azagra y Romero, 2012, pp.162-205) y entendemos que siguen manteniendo, si cabe, idéntica o mayor vigencia: a) un nuevo proyecto político para Europa; b) liderar la refundación moral de la economía de mercado; c) proponer un discurso renovado sobre la calidad de la democracia frente a cualquier tentación autoritaria; d) escuchar las causas profundas que subyacen en los nuevos movimientos sociales y la nuevas geografías del malestar; e) construir un nuevo discurso sobre el papel del Estado y la autonomía de la política sobre los mercados y los grandes monopolios globales; f) impulsar estrategias claras de adaptación a la crisis climática; g) impulsar políticas públicas en favor de nuevos modelos productivos y modelos de crecimiento; h) apostar de forma decidida por la sociedad digital; i) proponer un programa creíble de reformas del Estado de Bienestar para hacerlo sostenible; j) hacer de la justicia social y ambiental uno de los elementos centrales del discurso; k) educación, formación e innovación como cuestión estratégica; 1) proponer un modelo coherente de gestión de la multiculturalidad. 
El futuro es un país extraño, decía mi maestro Josep Fontana (2013). Y mucho más en tiempos oscuros como los actuales. Solía repetir que su programa máximo, no muy alejado de los ideales ilustrados, seguía siendo "el mayor grado de libertad posible con el mayor grado de igualdad y fraternidad posible". Sigue siendo el horizonte al que aspirar y estamos obligados a cartografiar este mundo nuevo, imaginar nuevos mecanismos e instrumentos de gobernanza, cooperación y solidaridad y desbrozar el camino y dejarlo lo más despejado posible para las siguientes generaciones. Si se lo propone y hace una lectura política solidaria y ambiciosa de la salida de esta situación crítica, la Unión Europea puede salir muy fortalecida y ser un actor geopolítico global muy relevante. También un referente moral en favor de la construcción de sociedades decentes. Alejada del modelo inaceptable del neoliberalismo radical y del modelo incompatible del comunismo ultraliberal impuesto en China. Europa es ahora percibida por muchos como el problema pero, pese a todo, en otra forma de entender y construir Europa sigue estando nuestra solución.

\section{Referencias}

Aixalà, A. (2014). Crisis económica y euroescepticismo (2007-2014). Propuestas para afrontar la crisis democrática europea. Madrid: Fundación Alternativas.

Alcalá, F., y Jiménez, F. (2018). Los costes económicos del déficit de calidad institucional y la corrupción en España. Bilbao: Fundación BBVA.

Ariño, A., y Romero, J. (2016). La secesión de los ricos. Barcelona: Galaxia de Gutenberg.

Azagra, J., y Romero, J. (2012). Desde la margen izquierda. Valencia: PUV.

Banco de España. (2020). Escenarios macroeconómicos de referencia del Covid-19 para la economía española (Documentos 2/2020). Madrid, 20 de abril. Recuperado de https://www.bde.es/f/webbde/GAP/Secciones/SalaPrensa/COVID-19/be2002-art1.pdf

Beck, U. (2012). La política económica de la inseguridad. El País, 27 de mayo.

Castells, M. (Ed.). (2018). Las crisis de Europa. Madrid: Alianza Editorial.

Castells, M. (2020). Después de la guerra. La Vanguardia, 28 de marzo.

De Lucas, J. (2015). Mediterráneo: el naufragio de Europa. Valencia: Tirant lo Blanch.

Dijkstra, L., Poelman, H., y Rodríguez-Pose, A. (2019). The Geography of EU discontent. Regional Studies. DOI: 10.1080/00343404.2019.1654603

Domínguez, I. (2020). Paolo Flores d'Arcais, filósofo: “Ahora una revolución es el mínimo indispensable". El Pais, 12 de abril.

Eatwell, R., y M. Goodwin, M. (2019). Nacionalpopulismo. Por qué está triunfando y de qué forma es un reto para la democracia. Barcelona: Península.

FMI. (2020). Informes de perspectivas de la economía mundial. Washington D.C., 14 de abril.

Recuperado

de https://www.imf.org/es/Publications/WEO/Issues/2020/04/14/weo-april-2020

Fontana, J. (2013). El futuro es un país extraño. Barcelona: Pasado y Presente.

Fukuyama, F. (2019). Identidad. La demanda de dignidad y las politicas de resentimiento. Barcelona: Planeta.

Guilluy, Ch. (2014). La France péripherique. Paris: Flammarion.

Guilluy, Ch. (2019). No society. El fin de la clase media occidental. Madrid: Taurus.

Habermas, J., et al. (2020). Europa solo podrá continuar existiendo si los europeos nos apoyamos mutuamente. Ctxt. Revista Contexto, (259). Recuperado de 
https:/ctxt.es/es/20200401/Firmas/31876/Habermas-Fischer-intelectuales-artistas-

llamamiento-coronavirus-solidaridad-comision-europea.htm

Judt, T. (2008). Sobre el olvidado siglo XX. Madrid: Taurus.

Krastev, I. (2019). Europa después de Europa. Valencia: PUV.

Les Gracques. (2020). Pour una stratégie de fonds propres (En Rapports de la serie "Coronavirus : regards sur une crise" de la Fondation Terra Nova). París, 10 de abril. Recuperado de http://nova.fr/system/contents/files/000/001/970/original/Terra_Nova__Pour_une_strategie_de_fonds_propres_100420.pdf?1586509868

Moreno, L. (2013). Europa asocial. Barcelona: Ediciones Península.

Moreno. L. (2020). Ingreso mínimo y ciudadano. Diario Público, 15 de abril.

Nachtwey, O. (2017). La sociedad del descenso. Precariedad y desigualdad en la era postdemocrática. Barcelona: Paidós.

OCDE. (2020). OECD Composite Leading Indicators News Release. Paris, 14 de abril. Recuperado de http://www.oecd.org/sdd/leading-indicators/composite-leadingindicators-cli-oecd-04-2020.pdf

OIT. (2020). Observatorio de la OIT segunda edición: El COVID-19 y el mundo del trabajo. Recuperado de https:/www.ilo.org/global/about-the-ilo/WCMS_740981/lang-es/index.htm

Ortega, A. (2017a). Sesenta años después, la UE navega sin rumbo y sin alma. El Espectador Global (Real Instituto Elcano), 7 de julio.

Ortega, A. (2017b). Momento vertical. El Espectador Global (Real Instituto Elcano), 6 de junio.

Pew Research Center. (2016). Euroskepticism Beyond Brexit. Recuperado de https://www.pewresearch.org/global/2016/06/07/euroskepticism-beyond-brexit/

Pinyol, G. (2016). Crisis de refugiados en la UE: diez cuestiones sobre las que reflexionar. Agenda Pública, 1 de marzo.

Rizzi, A. (2019). Treinta años después, un telón moral divide Europa. El País, 2 de octubre.

Romero, J. (2013). De nuevo la Cuestión Social en Europa. Una visión alternativa a la del pensamiento conservador y agenda para la investigación. Scripta Nova. Revista Electrónica de Geografia y Ciencias Sociales, XVII(444). Recuperado de http://www.ub.es/geocrit/sn/sn-444.htm

Romero, J. (2019). Sobre las geografías del malestar en Europa. Papeles de relaciones ecosociales y cambio global, (147), 61-72.

Romero, J. et al. (2019). Geografía del despilfarro en España. Valencia: Publicaciones de la Universidad de Valencia.

Rosanvallon, P. (2012). La sociedad de los iguales. Madrid: RBA.

Sebastián, C. (2019). Para que España funcione. Barcelona: Galaxia de Gutenberg.

Sennett, R. (2006). La cultura del nuevo capitalismo. Madrid: Anagrama.

Standing, G. (2011). El precariado. Barcelona: Pasado y Presente.

Standing, G. (2017). La corrupción del capitalismo. Barcelona: Pasado y Presente.

Torreblanca, J. I. (2011) Cinco razones por las que Europa se resquebraja. El País, 15 de mayo.

Traverso, E. (2019). Melancolía de izquierda. Después de las utopías. Barcelona: Galaxia de Gutenberg.

Vacas, C. (2019). El preocupante adelgazamiento de la clase media. Ctxt. Revista Contexto, (245). Recuperado de https://ctxt.es/es/20191030/Politica/29200/clase-mediadesigualdad-consumo-estabilidad-crisis-vacas-soriano.htm 
VV AA (2020). Coronavirus: regards sur une crise. (Rapports de la serie "Coronavirus: regards sur une crise" de la Fondation Terra Nova). París, 23 de marzo. Recuperado de http:/tnova.fr/notes/coronavirus-regards-sur-une-crise-c54221c5-0d55-4c47-b9cc5d6c50abee 95 